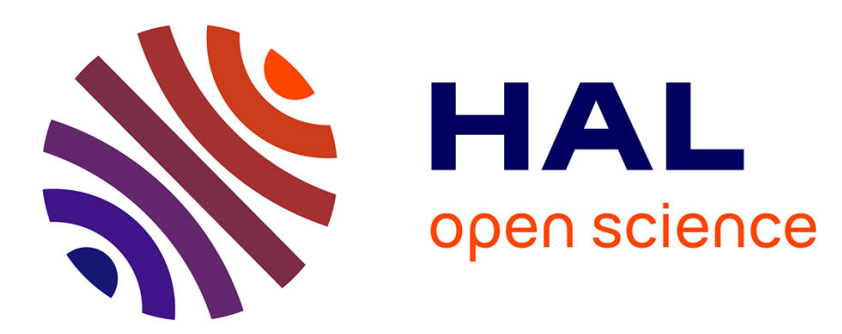

\title{
A Robust Differentiator-Controller Design for an Electropneumatic System
}

\author{
Mohamed Smaoui, Xavier Brun, Daniel Thomasset
}

\section{To cite this version:}

Mohamed Smaoui, Xavier Brun, Daniel Thomasset. A Robust Differentiator-Controller Design for an Electropneumatic System. 44th IEEE CDC, Dec 2005, Seville, Spain. pp.4385-4390, 10.1109/CDC.2005.1582852 . hal-02063794

\section{HAL Id: hal-02063794 \\ https://hal.science/hal-02063794}

Submitted on 20 Mar 2019

HAL is a multi-disciplinary open access archive for the deposit and dissemination of scientific research documents, whether they are published or not. The documents may come from teaching and research institutions in France or abroad, or from public or private research centers.
L'archive ouverte pluridisciplinaire HAL, est destinée au dépôt et à la diffusion de documents scientifiques de niveau recherche, publiés ou non, émanant des établissements d'enseignement et de recherche français ou étrangers, des laboratoires publics ou privés. 


\title{
A Robust Differentiator-Controller Design for an Electropneumatic System
}

\author{
M. Smaoui, X. Brun and D. Thomasset \\ Laboratoire d'Automatique Industrielle - INSA de Lyon \\ Bât Antoine de SAINT-EXUPERY, 25, avenue Jean Capelle 69621Villeurbanne Cedex, France \\ Tel: (33) 472438881 Fax: (33) 472438535
}

\begin{abstract}
In this paper, a robust differentiator via sliding mode is studied. A comparative study between the robust differentiator and a classical one is presented. Experimental results of the proposed sliding mode differentiator in the context of third order sliding mode controller for an electropneumatic system are given to illustrate the developments.
\end{abstract}

\section{NOMENCLATURE}

$b \quad$ viscous friction coefficient $(\mathrm{N} / \mathrm{m} / \mathrm{s})$

$k \quad$ polytropic constant

$M \quad$ total load mass $(\mathrm{kg})$

$p \quad$ pressure in the cylinder chamber $(\mathrm{Pa})$

$q_{m} \quad$ mass flow rate provided from servodistributor to cylinder chamber $(\mathrm{kg} / \mathrm{s})$

$r \quad$ perfect gas constant related to unit mass $(\mathrm{J} / \mathrm{kg} / \mathrm{K})$

$S \quad$ area of the piston cylinder $\left(\mathrm{m}^{2}\right)$

$T$ temperature $(\mathrm{K})$

$V \quad$ volume $\left(\mathrm{m}^{3}\right)$

$y, v, a$ position $(\mathrm{m})$, velocity $(\mathrm{m} / \mathrm{s})$ acceleration $\left(\mathrm{m} / \mathrm{s}^{2}\right)$

$\varphi($.$) \quad leakage polynomial function (\mathrm{kg} / \mathrm{s})$

$\psi($.$) polynomial function (\mathrm{kg} / \mathrm{s} / \mathrm{V})$

$l \quad$ length of stroke $(\mathrm{m})$

$T_{s} \quad$ sample time

Subscript

ext external

$D \quad$ dead volume

$S \quad$ supply

$\mathrm{N} \quad$ chamber $\mathrm{N}$

$\mathrm{P}$ chamber $\mathrm{P}$

d desired

\section{INTRODUCTION}

In many industrial environments and according to control engineering practice, it is necessary to minimize the number of sensors. This is why, the engineer must use other procedures allowed obtaining the signals.

Many schemes for the estimation of states variables have been proposed in recent years. Some of these methods are based on nonlinear observer theory such as high gain observer [1], sliding mode observer [2] and backstepping observer [3]. However, nonlinear state observer are difficult to implement when poor knowledge on the system dynamics is available. Therefore, research on modeling and identification is necessary to improve the performance of observers.

Another attractive method for the estimation of states variables, especially for mechanical systems, is the numerical differentiation. Indeed, Differentiators are a very useful tools to determine and estimate signals. For example, for mechanical systems, the velocity and acceleration can be computed from the position measurements using differentiators. However, the design of an ideal differentiator is a difficult and a challenging task. In [4], the author discuss the properties and the limitations of two different structures of linear differentiation systems. A predictive algorithm which is applied to angular acceleration measurements is presented in [5]. A robust first order differentiator via high order sliding mode technique is proposed in [6]. The differentiator considered features simple form and easy design. It may be employed in real-time control systems.

In addition, pneumatic actuators are one of the most common type of industry actuators [7]. The traditional and widely used approach to the control of electropneumatic systems is a fixed gain linear controller, based on the local linearization of the nonlinear dynamics about a nominal operating point [8]. This method relies on the key assumption of small range operation for the linear model to be valid. When the required operation range is large, the linear controller is likely to perform poorly or to be unstable. The harmful effect is due to the limitation of the linear feedback controller tolerance for the adverse effect of the nonlinearities or parameters variations.

When a fixed gain linear controller cannot satisfy the control requirement, it is natural to investigate other controllers. In recent years, a number of investigations have been conducted on feedback linearization [9], fuzzy control algorithms [10], backstepping control [11], adaptive control [12], standard sliding mode control [13], and high order sliding mode [14].

All of the previous mentioned feedback controllers require generally measurements of acceleration for feedback. However, accelerometer is seldom used in practical drive systems. Indeed, The use of accelerometers adds cost, energy consumption, increase the complexity of the overall system (the accelerometer is mounted to the load in displacement), and reduces its reliability. 
In this paper, a robust differentiator via sliding mode [6] which is applied to acceleration measurements will be introduced. The goal is to show the importance of the choice of the differentiator design on the control of an electropneumatic system.

The following section present the robust differentiator via second order sliding mode. Simulation results are presented to compare the robust differentiator to a classical one. Section III describes the model of the electropneumatic actuator and states the problem of interest. Section IV deals with the design of the control law via high order sliding mode technique. Section $\mathrm{V}$ will be devoted to the experimental results. Both sets of results will be compared according to an industrial benchmark. Section VI concludes the paper.

\section{A Robust DifFERENTIATOR Via SECOND ORdER SLIDING MODE}

\section{A. The robust differentiator}

The sliding mode technique is an attractive approach [15]. The primary characteristic of SMC is that the feedback signal is discontinuous, switching on one or several manifolds in the state-space. When the state trajectory crosses each discontinuity surfaces in the state-space, the structure of the feedback system and hence its dynamics will be altered. Under certain circumstances, all motions in the neighborhood of a manifold are directed towards the manifold and, thus, a sliding motion on a predefined subspace of the state-space is established in which the system state repeatedly crosses the switching surfaces. This mode has useful invariance properties even in the presence of uncertainties in the plant model and, therefore, is a good candidate for robust tracking control of uncertain nonlinear systems [13][16].

Specific drawback presented by the classical sliding mode techniques is the chattering phenomenon [17]. The chattering phenomenon is generally perceived as motion, which oscillates about the sliding manifold. In order to overcome this drawback, a research activity aimed at finding a continuous control action, robust against uncertainties, guaranteeing the attainment of the same control objective of the standard sliding mode approach has been carried out in recent years. The results algorithms, turned out to belong to the class of second order sliding mode control algorithms [17]-[20].

In general, any 2-sliding controller needs the sliding surface and it derivative to be made available and is determined by the equalities $s=\dot{s}=0$. The super twisting algorithm does not requires the time derivative of the sliding variable [18]. In this section, a robust differentiator via sliding mode technique is studied. Indeed, a robust exact differentiation via sliding mode technique is proposed in [6]. The differentiator considered features simple form and easy design. It was synthesized to be employed in real-time control systems.
Without lost of generality, let input signal $f(t)$ be a measurable function and let it consist of a base signal having a derivative with Lipschitz's constant $\mathrm{C}>0$. In order to differentiate the input signal, consider the auxiliary equation $\dot{x}=u$

Consider now the following sliding surface which represent the difference between $x$ and $f(t)$

$s=x-f(t)$

By differentiating $s$, it leads to the following relationship

$\dot{s}=u-\dot{f}(t)$

The super twisting algorithm defines the control law $u$ as

$u=u_{1}-\lambda|s| \frac{1}{2} \operatorname{sgn}(s)$

with

$\dot{u}_{1}=-w \operatorname{sgn}(s)$

where $w, \lambda>0$. Here $u$ is the output of the differentiator. Indeed, the super twisting algorithm converges in finite time, so the following relationship can be obtained in finite time :

$\dot{x}-\dot{f}(t)=u-\dot{f}(t)=0$

or

$u=\dot{f}(t)$

The corresponding sufficient conditions for finite time convergence are [6]:

$w>C$

$\lambda^{2} \geq 4 C \frac{w+C}{w-C}$

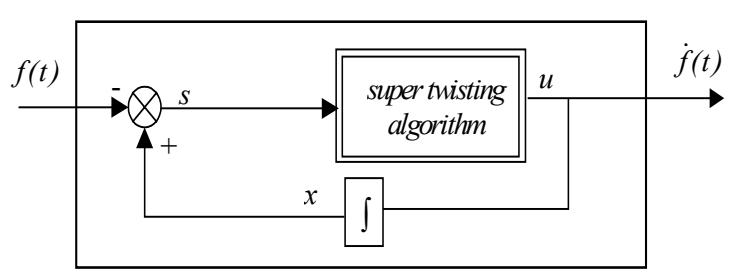

Fig.1. The structure of the differentiator

Figure 1 presents the structure of the differentiator. The separation principle is fulfilled for the proposed differentiator. A combined differentiator-controller output feedback preserve the main features of the controller with the full state available [20].

\section{B. Simulation results}

Firstly, the input signal is chosen as:

$$
f(t)=10 \sin (t)+0.02 \cos (40 t)
$$

Figure 2 presents the output of the differentiator and the ideal derivative of $f(t)(\dot{f}(t)=10 \cos (t)-0.8 \sin (40 t))$.

It is noticed that the robust differentiator output and the analytical derivative of the function are identical in a remarkable way. However, the choice of a method of 
derivation results from a compromise between the noise level and the phase delay between the output of the differentiator and the ideal derivative. Richard [21] has presented a comparative study between some differentiation algorithms in real time. Among these algorithms, that which offers the best compromise between the level of noise on the derived signal and the phase delay, is given by the following equation:

$$
\dot{x}_{n}=\frac{x_{n}-x_{n-2}}{2 T_{s}}
$$

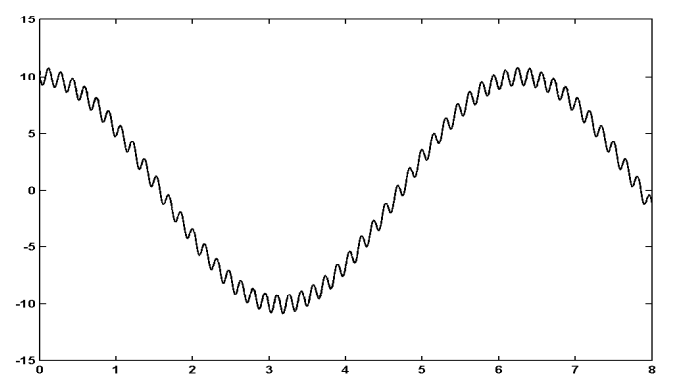

Fig.2. Simulation results

In order to compare the differentiation algorithm (11) to the differentiator via sliding mode technique, a sinusoidal signal with noise was applied as an input. The output of the two differentiators as well as the analytical derivative are reproduced in figures 3 and 4 .

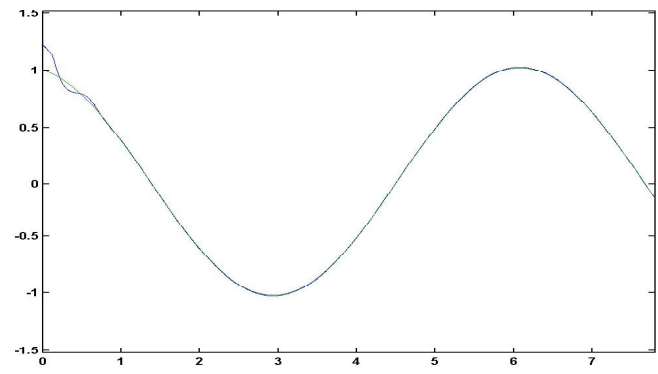

Fig.3. Derivative of signal in the presence of a noise: robust differentiator

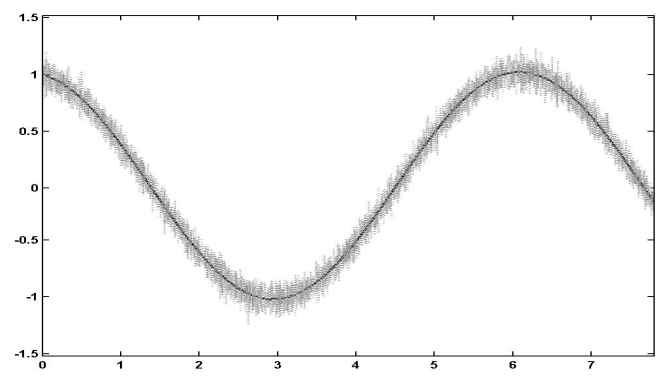

Fig.4. Derivative of signal in the presence of a noise: classical differentiator

On Figure 3, one notices that the robust differentiator output converges towards the analytical derivative in a finite time. The differentiator is insensitive to high frequency components of the input signal while the output of the differentiation algorithm (11) consists of the accurate derivative and some high-frequency noise (see figure 4). The use of this last in the context of controlling electropneumatic system (for example to calculate acceleration from velocity) introduced inevitably the chattering phenomena.

As indicated previously, the choice of a differentiator results from a compromise between the noise level and phase delay. The relative importance of these two criteria depends on the experimental context, it is difficult to show the superiority of a differentiation algorithm in the absence of experimental data. For that, we try thereafter to compare the two differentiators and their influences on the control of an electropneumatic system.

\section{Electropneumatic System Modeling}

The considered system (figure 5) is a linear inline double acting electropneumatic servo-drive using a single rod controlled by two three-way servodistributors. The actuator rod is connected to one side of the carriage and drives an inertial load on guiding rails. The total moving mass is 17 $\mathrm{kg}$.

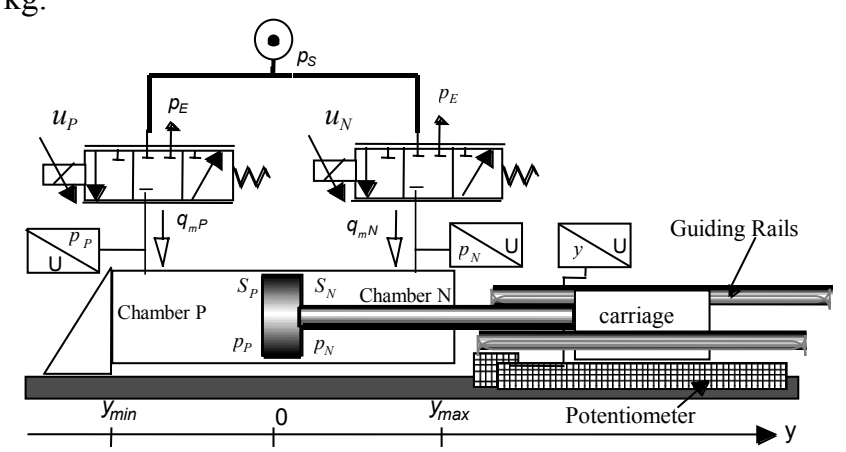

Fig.5. The electropneumatic system

The electropneumatic system model can be obtained using three physical laws: the mass flow rate through a restriction, the pressure behavior in a chamber with variable volume and the fundamental mechanical equation.

The pressure evolution law in a chamber with variable volume is obtained assuming the following assumptions [22]: air is a perfect gas and its kinetic energy is negligible. The pressure and the temperature are supposed to be homogeneous in each chamber. The process is polytropic and characterized by coefficient $k$. Moreover, the electropneumatic system model is obtained by combining all the previous relations and assuming that the temperature variation is negligible with respect to average and equal to the supply temperature. The dynamics of the servodistributors may be neglected. So, the servodistributors model can be reduced to a static one described by two relationships $q_{m} P\left(u_{P}, p_{P}\right)$ and $q_{m} P\left(u_{N}, p_{N}\right)$ between the mass flow rates $q_{m} P$ and $q_{m} N$, the input voltages $u_{P}$ and $u_{N}$, and the output pressures.

The mechanical equation include pressure force, viscous 
friction and an external constant force due to atmospheric pressure. So the following equation gives the model of the above system:

$$
\left\{\begin{array}{l}
\frac{d y}{d t}=v \\
\frac{d v}{d t}=\frac{1}{M}\left[S_{P} p_{P}-S_{N} p_{N}-b v-F_{e x t}\right] \\
\frac{d p_{P}}{d t}=\frac{k r T}{V_{P}(y)}\left[q_{m}\left(u_{P}, p_{P}\right)-\frac{S_{P}}{r T} p_{P} v\right] \\
\frac{d p_{N}}{d t}=\frac{k r T}{V_{N}(y)}\left[q_{m^{N}}\left(u_{N}, p_{N}\right)+\frac{S_{N}}{r T} p_{N} v\right]
\end{array}\right.
$$

Where:

$$
\left\{\begin{array} { l } 
{ V _ { P } ( y ) = V _ { P } ( 0 ) + S _ { P } y } \\
{ V _ { N } ( y ) = V _ { N } ( 0 ) - S _ { N } y }
\end{array} \text { with: } \left\{\begin{array}{l}
V_{p}(0)=V_{D P}+S_{P} \frac{l}{2} \\
V_{N}(0)=V_{D N}+S_{N} \frac{l}{2}
\end{array}\right.\right.
$$

are the piping volumes of the chambers for the zero position and $V_{D(\text { Por } N)}$ are dead volumes present on each extremities of the cylinder.

The main difficulty for model (12) is to know the mass flow rates $q_{m} P$ and $q_{m}$. This model is issue of experimental measurement [23] and therefore a mathematical model for a static flow stage has been obtained from a polynomial approximation [24] affine in control (13).

$q_{m}(u, p)=\varphi(p)+\psi(p, \operatorname{sgn}(u)) \times u$

$\psi()>$.0 over the physical domain.

The system use two three-way proportional servodistributors. Generally, It is supposed that these two servodistributors are equivalent to one five-way proportional servodistributor when they are controlled with input of opposite signs [25]. In this case, the nonlinear affine model is then given by equation:

$$
\underline{\dot{x}}=f(\underline{x})+g(\underline{x}) u
$$

where $\underline{x}, f(\underline{x})$ and $g(\underline{x})$ are given by the following relations:

$$
\underline{x}=\left(y, v, p_{P}, p_{N}\right)^{T}
$$

$$
f(\underline{x})=\left(\begin{array}{c}
v \\
\frac{1}{M}\left[S_{P} p_{P}-S_{N} p_{N}-b v-F_{\text {ext }}\right] \\
\frac{k r T}{V_{P}(y)}\left[\varphi\left(p_{P}\right)-\frac{S_{P}}{r T} p_{P} v\right] \\
\frac{k r T}{V_{N}(y)}\left[\varphi\left(p_{N}\right)+\frac{S_{N}}{r T} p_{N} v\right]
\end{array}\right)
$$

$$
g(\underline{x})=\left(\begin{array}{c}
0 \\
0 \\
\frac{k \cdot r \cdot T}{V_{P}(y)} \cdot \psi\left(p_{P}, \operatorname{sgn}(u)\right) \\
-\frac{k \cdot r \cdot T}{V_{N}(y)} \cdot \psi\left(p_{N}, \operatorname{sgn}(-u)\right)
\end{array}\right)
$$

Using the electropneumatic model (14), the control law is synthesized in the next section. The aim of the control law is to respect a good accuracy in term of position tracking for a desired trajectory. The relative degree of the position is three. This means that the electropneumatic system can only track position trajectory at least three times differentiable. The desired trajectory have been carefully chosen in order to respect the differentiability required (see Figure 6).

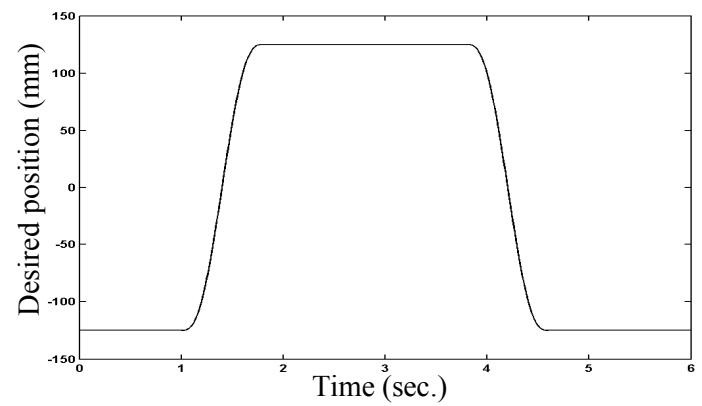

Fig. 6. Desired position (mm)

\section{THIRD ORDER SLIDING MOdE CONTROLleR}

The effective application of sliding mode control to pneumatic systems needs to resolve the problem related to the chattering phenomenon and the switching control signals [13]. High order sliding modes appear to be suitable to counteract this problems.

Let $s(x, t)$ the sliding variable, the $r^{\text {th }}$ order sliding mode is determined by $s=\dot{s}=\ddot{s}=\ldots=s^{(r-1)}=0$, which form an r-dimensional condition on the state of the dynamic system. In general, any $r$-sliding controller needs $s, \dot{s}, \ddot{s}, \ldots, s^{(r-1)}$ to be made available, i.e., a 3 -sliding controller needs $s, \dot{s}, \ddot{s}$ to be made available[18].

The aim of the control law is to respect a good accuracy in term of position tracking for a desired trajectory. Let us define the sliding surface by

$s=\left(y-y^{d}\right)$

which represent the position error. The relative degree of the position is equal to three. It is easy to check that the control input appears explicitly in the $3^{\text {rd }}$ total time derivative of $s$. In this case, a first and second order sliding mode cannot be used. A $3^{\text {rd }}$ order sliding mode algorithm appear to be suitable to counteract this problems.

By using the model (14), the following equations are obtained:

$$
\begin{aligned}
& \dot{s}=\left(v-v^{d}\right) \\
& \ddot{s}=\left(a-a^{d}\right) \\
& \dddot{s}=\Delta \chi(\underline{x})+\chi_{n}(\underline{x})+\beta(\underline{x}) \times u
\end{aligned}
$$

with 


$$
\begin{aligned}
\chi_{n}= & -\frac{k v}{M}\left[\left(\frac{S_{p}^{2} p_{P}}{V_{P}(y)}+\frac{S_{N}^{2} p_{N}}{V_{N}(y)}\right)\right]-j^{d} \\
\Delta \chi(\underline{x})= & \frac{k r T}{M}\left[\frac{S_{p}}{V_{p}(y)} \varphi\left(p_{p}\right)-\frac{S_{N}}{V_{N}(y)} \varphi\left(p_{N}\right)\right]-\frac{b}{M^{2}}\left(S_{P} p_{P}\right. \\
& \left.-S_{N} p_{N}-b v-F_{e x t}\right) \\
\beta(x)= & \frac{S_{P}}{M} \frac{k r T}{V_{P}(y)} \psi\left(p_{P}, \operatorname{sgn}(u)\right)+\frac{S_{N}}{M} \frac{k r T}{V_{N}(y)} \psi\left(p_{N}, \operatorname{sgn}(-u)\right)
\end{aligned}
$$

$\Delta \chi(\underline{x})$ contains all uncertainties, i.e., the leakage polynomial function and friction. Using the static feedback:

$u=\beta^{-1}(\underline{x})\left(-\chi_{n}(\underline{x})+w\right)$

$w$ is the new control input. One gets :

$\dddot{s}=\Delta \chi(\underline{x})+w$

Where $\Delta \chi(x)$ is a bounded function.

A $3^{\text {rd }}$ order sliding mode controller based on optimal linear quadratic control is presented in [26]. A family of $r$ sliding mode controllers with finite time convergence for any natural number $r$ is presented in [27]. In this paper, a $3^{\text {rd }}$ order sliding mode controller from this family is used.

In this case, only a single scalar parameter is to be adjusted. Indeed, the new control input $w$ can be chosen as follows [27]:

$$
w=-\lambda \operatorname{sgn}\left(\ddot{s}+2\left(|\dot{s}|^{3}+|s|^{2}\right)^{\frac{1}{6}} \operatorname{sgn}\left(\dot{s}+|s|^{\frac{2}{3}} \operatorname{sgn}(s)\right)\right)
$$

\section{EXPERIMENTAL RESULTS}

The proposed controller was implemented using a dSpace DS1104 controller board with a dedicated digital signal processor. The sensed signals, all analog, were run through the signal conditioning unit before being read by the A/D converter. The velocity cylinder is determined by analog differentiation and low-pass filtering of the position. The position is given by an analog potentiometer. The gain controller $\lambda$ has been tuned as $\lambda=200$.

Firstly, the classical differentiator (11) is used to recover the acceleration information. Figures 7, 8 and 9 shows the estimated acceleration and the desired acceleration, the position error, and the control input.

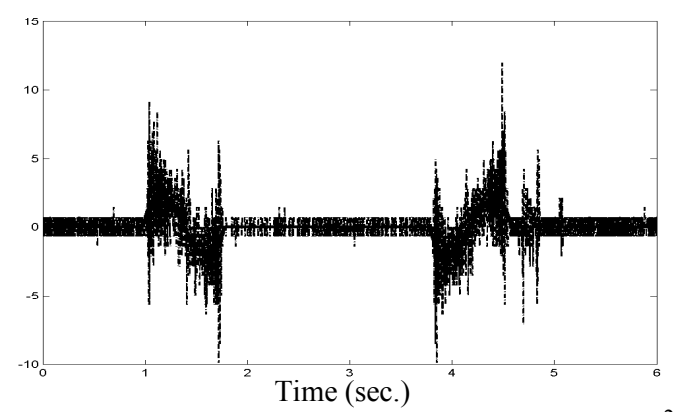

Fig.7. Acceleration and desired acceleration $\left(\mathrm{ms}^{-2}\right)$
The maximum position error is about $1.8 \mathrm{~mm}$, i.e. $0.7 \%$ of the total displacement magnitude (see figure 8) However, the control input is affected by the chattering phenomena. This due to the acceleration signal. Indeed, the noise level is significant (see figure 7), so the control input which depends on acceleration is affected. It is clear that if the value of controller parameter $\lambda$ is decreased or the function sign is replaced by a smooth function, the control input is not affected by the chattering phenomena. But in this case, the position error becomes larger.

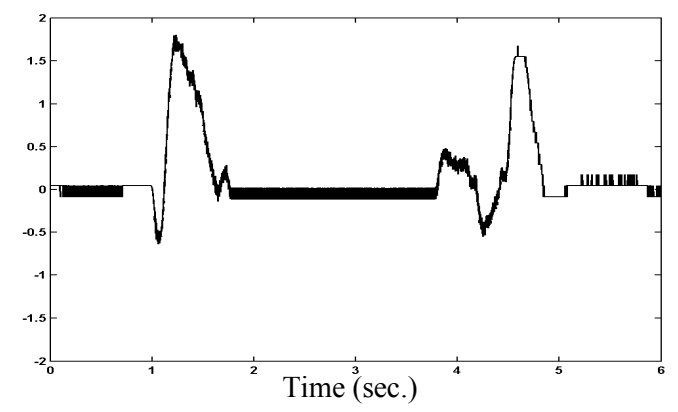

Fig.8. Position error (mm)

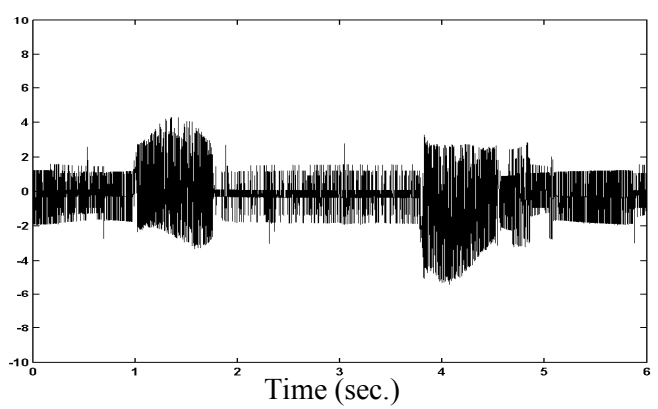

Fig. 9. Control input (V)

Now, the robust differentiator via sliding mode technique is used to recover the acceleration signal. Some experiment results are provided here to demonstrate the effectiveness of the combined controller/differentiator.

Figure 10 shows the estimated acceleration and the desired acceleration. It is important to note that, although the velocity signal is obtained by analog differentiation of the position (in other words, the velocity signal contains some small high frequency noise), the acceleration signal is smooth. Moreover, the resulting acceleration is without harmful delay. This improve the effectiveness of the controller. Indeed, the maximum position error is about 1 $m m$ (see figure 11), i.e., twice smaller than the maximum position error obtained with the same controller combined with the classical differentiator.

Figure 12 displays the control input which is not affected by the chattering effect.

From these experimental results, we can conclude that the use of the robust differentiator via sliding mode makes it possible to ensure a better derivation of velocity in real time and thus to ensures a good accuracy in term of position tracking for a desired trajectory. 


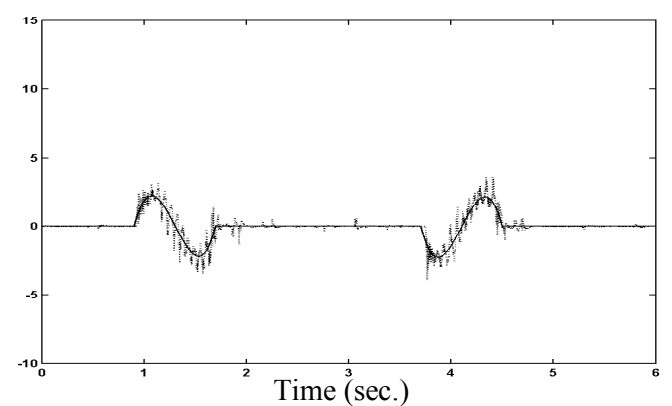

Fig.10. Acceleration and desired acceleration $\left(\mathrm{ms}^{-2}\right)$

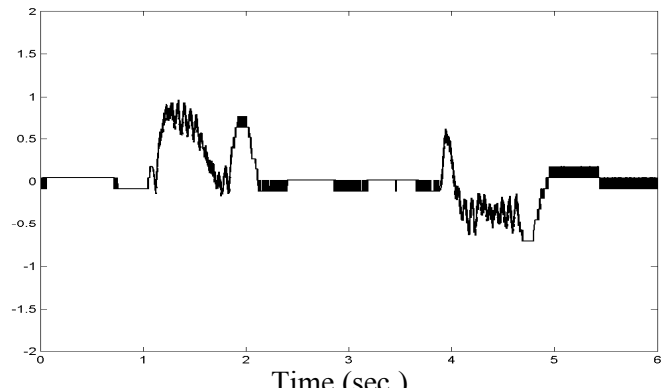

Fig.11. Position error (mm)

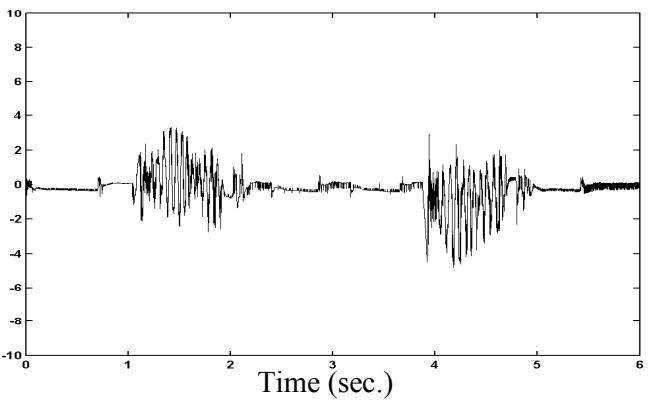

Fig.12. Control input (V)

\section{CONCLUSION}

In this paper, a combined robust differentiator and robust controller via high order sliding mode for an electropneumatic system is presented. Experiment results are carried out in order to show the effectiveness of this structure.

The differentiator unit have been used to estimate the acceleration. The method shows remarkable results. The proposed algorithm efficiently attenuates the noise related to differentiating the velocity signal while maintaining the delay differentiation properties. This improvement permit jointly to reduce the noise in control signal and so the reduction of chattering effect, and to increase the tracking performance in term of position tracking.

\section{REFERENCES}

[1] J.P Gauthier, H. Hammouri and S. Othman, "A simple observer for nonlinear systems applicationsto bioreactors," IEEE Trans. on Automatic Control, vol. 37, no 6, 1992, 875-880.

[2] .J.E. Slotine and W. Li, Applied Nonlinear Control, Prentice-Hall 461p. 1991.

[3] A.J. Krener and W. Kang "Locally convergent nonlinear observers," Siam J. Control Optim, vol. 42, No. 1, 2003, pp. 155-177.
[4] S. Ibrir, "Linear time-derivative trackers," Automatica, vol. 40, 2004, pp. 397-405.

[5] S. Valiviita, S.J. Ovaska, "Delayless recursive differentiator with efficient noise attenuation for control instrumentation," Signal Processing, vol. 69, 1998, pp. 267-280.

[6] A. Levant, "Robust exact differentiation via sliding mode technique," Automatica, vol.34, no. 3, 1998, pp. 379-384

[7] K.A. Edge, "The control of fluid power systems responding to the challenge," Journal of Systems and Control Engineering, vol. 211, no. 12, 1997, pp. 91-110.

[8] X. Brun, S. Sesmat, D. Thomasset and S. Scavarda, "A comparative study between two control laws of an electropneumatic actuator," In European Control Conference ECC'99, Karlsruhe, [CD Rom], reference F1000-5, 1999, 6p.

[9] T. Kimura, S. Hara, T. Fujita and T. Kagawa, "Feedback linearization for pneumatic actuator systems with static fiction," Control engineering practice, vol. 5, no. 10, 1997,1385-1394.

[10] M. Parnichkun, and C. Ngaecharoenkul, "Kinematics control of a pneumatic system by hybrid fuzzy PID," Mechatronics, vol. 11, 2001, pp. 1001-1023.

[11] M. Smaoui, X. Brun and D. Thomasset, "A robust multivariable control for an electropneumatic system using backstepping design," In IFAC Symposium on Nonlinear Control Systems, NOLCOS'04, Stuttgart, Germany, 2004, pp. 1193-1198.

[12] B. Li, Z. Li, and Y. Xu, "Study on adaptive control for a pneumatic position servo system," Advances in Modelling and Analysis,vol.49, no. 2,1997 , pp. $21-28$.

[13] M. Bouri and D. Thomasset, "Sliding Control of an Electropneumatic Actuator Using an Integral switching Surface," IEEE Trans. on control syst. technology, vol. 9, no. 2, 2001, pp. 368-375.

[14] M. Smaoui, X. Brun and D. Thomasset, "A Combined First and Second Order Sliding Mode Approach for Position and Pressure Control of an Electropneumatic System," In American Control Conference, ACC'05, Portland, Oregon, USA, 2005, pp. 3007-3012

[15] V.I. Utkin, "Variable structure systems with sliding modes," IEEE Trans. Automat. Control, vol.26, no.2, 1977, pp. 212-222.

[16] J. Song and Y. Ishida, "A robust sliding mode control for pneumatic servo systems," Int. J. Engng Sci., vol.35, no. 8, 1997, pp. 711-723

[17] G. Bartolini, A. Ferrara and E. Usai, "Chattering avoidance by secondorder sliding mode control," IEEE Trans. on Automat. Control, vol.43, no.2, 1998, pp.241-246.

[18] A. Levant, "Sliding order and sliding accuracy in sliding mode control," Int. J. of Control, vol. 58, no.6, 1993, pp.1247-1263.

[19] L. Fridman, and A. Levant, "Higher order sliding modes, eds. Sliding Mode Control in Engineering," Marcel Dekker, Inc., 2002, pp.53-101.

[20] A. Levant, "Higher-order sliding modes, differentiation and outputfeedback control," Int. J. of Control, vol. 76, no. 9, 2003, pp.924-941.

[21] E. Richard, "De la commande linéaire et non linéaire en position des systèmes électropneumatiques," PhD thesis [in french],, Lyon, INSA of Lyon,, 1990, 291p.

[22] J.L. Shearer, "Study of pneumatic processes in the continuous control of motion with compressed air," Parts I and II. Trans. Am. Soc. Mech. Eng., vol. 78, 1956, pp. 233-249.

[23] S. Sesmat and S. Scavarda, "Static characteristics of a three way servovalve," In $12^{\text {th }}$ Aachen Conference on Fluid Power Technology, Aachen, Germany, 1996, pp. 643-652

[24] M. Belgharbi, D. Thomasset, S. Scavarda and S. Sesmat, "Analytical model of the flow stage of a pneumatic Servodistributor for simulation and nonlinear control," In the Sixth Scandinavian International Conference on Fluid. Power, SICFP'99, Tampere, Finland, 1996, pp. 847-860.

[25] X. Brun, D. Thomasset and E. Bideaux, "Influence of the process design on the control strategy: application in electropneumatic Field," Control Engineering Practice, vol.10, no. 7, 2002, pp. 727-735.

[26] S. Laghrouche, M. Smaoui, and F. Plestan, "Robust control of electropneumatic actuator by 3-order sliding mode", in Conference on Decision and Control CDC'04, Paradise Island, The Bahamas, 2004

[27] A Levant, "Universal SISO sliding-mode controllers with finite-time convergence," IEEE Trans. Automat. Control, vol.46, no.9, 2001, pp. $1447-1451$. 